\title{
Histiocitosis de células de Langerhans con compromiso vertebral
}

\author{
Manuel Giraldo-Grueso ${ }^{1 *}$, María C. Villegas ${ }^{2}$, David L. Rodríguez ${ }^{3}$ y Edison Rodríguez ${ }^{4}$ \\ ${ }^{1}$ Fundación Cardioinfantil-Instituto de Cardiología; ${ }^{2}$ Hospital Universitario San Ignacio, Bogotá; ${ }^{3}$ Universidad Pedagógica y Tecnológica de Colombia; \\ ${ }^{4}$ Hospital San Rafael de Tunja, Boyacá. Colombia
}

\begin{abstract}
Resumen
Introducción: La histiocitosis de células de Langerhans (HCL) es un trastorno histiocítico raro y su incidencia exacta se mantiene desconocida; se ha diagnosticado en todos los grupos de edad, pero es más común en los primeros 3 años de vida. Se caracteriza por lesiones únicas o múltiples de tipo osteolítico causadas por proliferación clonal de células histológicamente similares a las células de Langerhans; su presentación clínica es heterogénea. Caso clínico: Presentamos el caso de una paciente de sexo femenino de 7 años, con dificultad para la marcha y debilidad progresiva en los miembros inferiores de 5 días de evolución. A la exploración física presenta hallazgos concordantes con síndrome piramidal e hipoestesias de miembros inferiores. Se realizó resonancia magnética (RM) de columna y tomografía computarizada de cráneo simple, que descartó patología intracraneal. En la RM de columna se detectó vertebra plana con extensión epidural y paravertebral, por lo que se inició manejo con esteroides y se indicó descompresión quirúrgica. Se realizó resección parcial y biopsia de la lesión. Debido a los hallazgos histológicos y la presencia de marcadores positivos para CD1a y CD207, se confirmó el diagnóstico de HCL. Conclusiones: La HCL es una enfermedad poco frecuente y de difícil diagnóstico por su presentación heterogénea. El granuloma eosinofilico y la vértebra plana como hallazgos imagenológicos pueden orientar el diagnóstico, aunque siempre se debe confirmar histológicamente.
\end{abstract}

Palabras clave: Histiocitosis de células de Langerhans. Granuloma. Lesión medular.

\section{Langerhans cell histiocytosis with vertebral involvement}

\section{Abstract}

Background: Langerhans cell histiocytosis $(\mathrm{LCH})$ is a rare disease, more common in the first three years of life. It is characterized by single or multiple osteolytic lesions due to clonal proliferation of cells histologically similar to Langerhans cells; its clinical presentation is heterogeneous. Case report: 7-year-old female patient with 5 days of progressive lower extremity weakness and difficulty to walk. Physical exam findings were consistent with pyramidal syndrome and lower extremities hypoesthesia. Magnetic resonance imaging (MRI) of spine and cranial computed tomography (CT) were performed. Intracranial pathology was ruled out. The MRI findings showed vertebra plana with epidural and paravertebral involvement, so treatment with steroids and surgical decompression initiated. Partial resection and biopsy of the lesion was performed. Due to histological findings and positive CD1a and CD207 markers, diagnosis of LCH was confirmed. Conclusions: $L C H$ is an

Correspondencia:

*Manuel Giraldo-Grueso

E-mail: manuelgiraldog@ hotmail.com
Fecha de recepción: 20-11-2017

Fecha de aceptación: 27-02-2018

DOI: 10.24875/BMHIM.M18000024
Disponible en internet: : 25-09-2018 Bol Med Hosp Infant Mex. 2018;75:309-312 www.bmhim.com

1665-1146/@ 2018. Hospital Infantil de México Federico Gómez, impreso por Permanyer México SA de CV, todos los derechos reservados. 
uncommon disease with a challenging diagnosis due to its heterogeneous clinical presentation. Eosinophilic granuloma and vertebra plana as imaging findings may guide the diagnosis. However, it should always be confirmed with histological evidence.

Key words: Langerhans cell histiocytosis. Granuloma. Spinal injury.

\section{Introducción}

La histiocitosis de células de Langerhans ( $\mathrm{HCL})$ es una enfermedad caracterizada por lesiones únicas o múltiples de tipo osteolítico, secundarias a una proliferación clonal de células histológicamente similares a las células de Langerhans en uno o varios órganos ${ }^{1}$.

En los niños, la histiocitosis se clasifica en clase I o histiocitosis $\mathrm{X}$; clase II o síndrome hemofagocítico (asociado a infección o familiar); y clase III o histiocitosis maligna, leucemia monocítica aguda y el verdadero linfoma histiocítico.

La HCL es un trastorno histiocítico raro y su incidencia exacta se mantiene desconocida. Se ha diagnosticado en todos los grupos de edad, pero es más común en los primeros 3 años de vida. La incidencia reportada se estima entre 3 y 5 casos por cada millón de niños y 1 a 2 casos por cada millón de adultos ${ }^{2,3}$.

La presentación clínica es heterogénea; varía según el sitio de la lesión y la edad de presentación clínica, siendo las más comunes las lesiones líticas en el hue$\mathrm{so}^{3}$. En la población pediátrica, el sitio más frecuente es el cráneo, en el $40 \%$ de los casos; en los adultos se presenta predominantemente en la mandíbula $(30 \%)$ y en las extremidades (17\%). Pocos casos de HCL se han reportado en la literatura con compromiso de cuerpos vertebrales en la población pediátrica ${ }^{3,4}$.

A continuación, se describe el caso de una paciente a quien se le diagnosticó HCL con compromiso vertebral y de tejidos blandos adyacentes.

\section{Caso clínico}

Paciente de sexo femenino, de 7 años de edad, que acude a consulta por un cuadro clínico de 5 días de evolución consistente en dificultad para la marcha asociada a múltiples caídas desde su propia altura y disminución progresiva de la fuerza en los miembros inferiores, sin otra sintomatología asociada.

Al examen de ingreso se encontraba sin alteración en sus signos vitales y con una exploración física general normal. En el examen neurológico no se encontró déficit en los pares craneales. Al evaluar la fuerza muscular, la paciente presentaba disminución de la fuerza en los miembros inferiores (4/5), sin alteración en los miembros superiores. Los reflejos miotendinosos mostraron hiperreflexia rotuliana y aquiliana bilateral junto con respuesta plantar extensora bilateral (signo de Babinski). Presentaba hipoestesia para todas las modalidades sensitivas, con nivel T10.

Al ingreso a la institución, la paciente fue valorada por pediatría. Por el hallazgo de síndrome piramidal e hipoestesias en los miembros inferiores, se sospechó lesión a nivel torácico, por lo que se solicitó resonancia magnética (RM) de columna y tomografía computarizada (TC) de cráneo simple para descartar otros diagnósticos diferenciales.

La TC descartó patología intracraneal; sin embargo, la RM de columna (Fig. 1) evidenció una lesión de señal intermedia en T1 y T2 comprometiendo el cuerpo vertebral T9, con fractura patológica por compresión axial con extensión al canal espinal y los tejidos blandos paravertebrales, condicionando compresión medular con mielopatía radiológica. El componente epidural presentó unos diámetros aproximados de $36 \times 33 \times$ $10 \mathrm{~mm}$; se asoció con una discreta alteración en la señal del muro posterior de los cuerpos vertebrales adyacentes por infiltración contigua. Dado el hallazgo de vertebra plana con extensión epidural y paraespinal en una niña de 7 años, se consideró, como primera posibilidad, HCL en T9 con compromiso por contigüidad de T8 y T10.

Por los hallazgos descritos se dio inicio al tratamiento con esteroides y se realizó descompresión quirúrgica con laminectomía de T8-T9, encontrando un tumor gris rojizo friable no aspirable, vascularizado, que comprometía los pedículos de T8-T9 y con invasión del canal raquídeo en el 100\%. Se realizó resección parcial y biopsia de la lesión.

La paciente presentó una evolución posquirúrgica adecuada, sin nuevo deterioro neurológico, con una recuperación completa de la fuerza y la sensibilidad en los miembros inferiores en la primera semana posoperatoria.

La valoración histológica del material resecado mostró una proliferación hipercelular de células, como linfocitos maduros, eosinófilos, neutrófilos, algunos plasmocitos y presencia de unas células grandes irregulares (algunas con núcleos con hendiduras, otras 


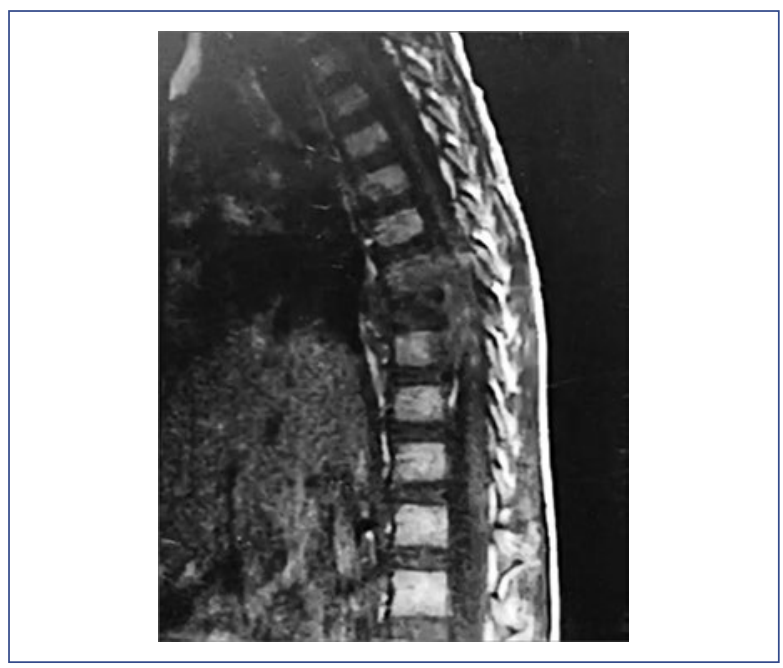

Figura 1. Resonancia magnética de columna en la que se evidenció una lesión de señal intermedia en T1 y T2 comprometiendo el cuerpo vertebral T9, con fractura patológica por compresión axial con extensión al canal espinal y los tejidos blandos paravertebrales, condicionando compresión medular con mielopatía radiológica.

con nucléolo prominente y citoplasma espumoso). Los hallazgos morfológicos descritos sugieren un trastorno linfoproliferativo, que incluía como primera posibilidad diagnóstica la HCL; se realizó inmunohistoquímica de la biopsia y se encontraron marcadores CD1a y CD207 positivos, confirmando el diagnóstico de HCL.

Posterior al diagnóstico de $\mathrm{HCL}$, la paciente fue sometida a tratamiento con vinblastina y prednisona por 6 semanas.

\section{Discusión}

La HCL es un trastorno histiocítico de etiopatogenia desconocida ${ }^{5,6}$. Tiene una sintomatología y una presentación clínica heterogéneas; es más común en la población pediátrica y afecta el sistema óseo en el $77 \%$ de los casos, la piel y las mucosas en el 39\%, los nódulos linfáticos en el $19 \%$ y el hígado en el $16 \%{ }^{5-7}$.

$\mathrm{Si}$ bien el $77 \%$ de las lesiones en la $\mathrm{HCL}$ son de compromiso óseo, la localización vertebral, como en la paciente descrita en este caso, es rara ${ }^{7}$. De acuerdo con la literatura, solo el 1-8\% de todos los casos tienen compromiso vertebral ${ }^{8,9}$. Usualmente, las lesiones multifocales se presentan en menores de 3 años, y las lesiones únicas ocurren en pacientes adultos.

La paciente descrita en este caso debutó con dificultad para la marcha y paraparesia espástica. Estos hallazgos también son poco frecuentes en pacientes con $\mathrm{HCL}$, pues los síntomas más comunes son la presencia de exantema, disnea, taquicardia, polidipsia, linfadenopatías y pérdida de peso ${ }^{10}$. La sintomatología se deriva de la localización de la lesión y del compromiso multisistémico. Dado el compromiso único vertebral de la paciente, la sintomatología es extraña y poco concordante con la $\mathrm{HCL}$.

En la HCL con compromiso vertebral, la manifestación más común es el granuloma eosinofílico, así como la presencia de un conglomerado de células de Langerhans, linfocitos, macrófagos, eosinófilos y células gigantes ${ }^{11}$. La imagen radiológica característica es el aplanamiento vertebral ${ }^{11}$, como presentaba la paciente.

El diagnóstico de HCL se realizó con una biopsia confirmatoria de la lesión, con histoquímica positiva para receptores CD1a y CD207. Siendo una enfermedad tan poco común y con sintomatología heterogénea, se deben plantear diagnósticos diferenciales. Las vértebras planas también se observan en enfermedades neoplásicas, como el sarcoma de Ewing, el osteosarcoma, el linfoma y la leucemia, y en patologías infecciosas como la tuberculosis y la osteomielitis ${ }^{11-13}$. También deben considerarse enfermedades de trastornos histiocíticos, como la enfermedad de Erdhei-Chester, el xantogranuloma juvenil y la linfocitosis hemofagocítica ${ }^{14}$.

En cuanto al tratamiento, se debe iniciar el enfoque diagnóstico con una estratificación del riesgo y clasificar la enfermedad dependiendo de cuántos sistemas compromete. La Histiocyte Society ${ }^{15}$ sugiere, para el tratamiento de la $\mathrm{HCL}$, una combinación de prednisona con vinblastina inicialmente por 6 semanas; este tratamiento ha demostrado poca toxicidad y excelentes resultados. Las dosis recomendadas son $40 \mathrm{mg} / \mathrm{m}^{2}$ al día de prednisolona por 4 semanas y $6 \mathrm{mg} / \mathrm{m}^{2}$ semanal de vinblastina por 6 semanas ${ }^{15}$.

La Histiocyte Society ${ }^{15}$ recomienda realizar seguimientos en el primer año de tratamiento por el riesgo de toxicidad de los medicamentos. Por el compromiso vertebral de la paciente descrita, se sugiere realizar un seguimiento clínico cada 6 semanas, pruebas de laboratorio (función hepática y renal, osmolaridad sanguínea y urinaria, hemograma) cada 3 meses, e imágenes diagnósticas solo si se sospecha una recidiva tumoral ${ }^{15}$.

La frecuencia de recidiva en los pacientes similares al caso presentado anteriormente es muy baja, cercana al $5 \%$, lo cual indica un buen pronóstico ${ }^{16}$. Si se evidencia algún tipo de recidiva, debe realizarse otro esquema con prednisolona, vinblastina y mercaptopurina. Se ha 
reportado hasta el $85 \%$ de éxito con este tratamiento de segunda línea ${ }^{17}$. El seguimiento se debe realizar con controles imagenológicos y bioquímicos.

El pronóstico en la enfermedad focal es muy bueno. En el caso de la enfermedad sistémica, el $60 \%$ de los pacientes que la presentan tienen un curso crónico, siendo necesario buscar otras líneas de tratamiento.

La HCL es una enfermedad poco frecuente, con una clínica heterogénea de difícil diagnóstico, y la presentación vertebral es muy rara. La presencia de vértebra plana orienta al diagnóstico, pero debe confirmarse con una evaluación histológica de la lesión.

\section{Responsabilidades éticas}

Protección de personas y animales. Los autores declaran que los procedimientos seguidos se conformaron a las normas éticas del comité de experimentación humana responsable y de acuerdo con la Asociación Médica Mundial y la Declaración de Helsinki.

Confidencialidad de los datos. Los autores declaran que han seguido los protocolos de su centro de trabajo sobre la publicación de datos de pacientes.

Derecho a la privacidad y consentimiento informado. Los autores han obtenido el consentimiento informado de los pacientes y/o sujetos referidos en el artículo. Este documento obra en poder del autor de correspondencia.

\section{Conflicto de intereses}

Los autores declaran no tener conflicto de intereses.

\section{Financiamiento}

Ninguno.

\section{Bibliografía}

1. Favara BE, Jaffe R. The histopathology of Langerhans cell histocytosis. Br J Cancer Suppl. 1994;23:17-23.

2. Carstensen $\mathrm{H}$, Ornvold K. The epidemiology of LCH in children in Denmark, 1975-89. Med Pediatr Oncol. 1993;21:387-8.

3. Baumgartner I, von Hochstetter A, Baumert B, Luetolf U, Follath F. Langerhans' cell histiocytosis in adults. Med Pediatr Oncol. 1997;28:9-14.

4. Haupt R, Minkov M, Astigarraga I, Schafer E, Nanduri V, Jubran R. Langerhans cell histiocytosis (LCH): guidelines for diagnosis, clinical work-up, and treatment for patients till the age of 18 years. Pediatr Blood Cancer. 2013;60:175-84.

5. McClain K, Jin H, Gresik V, Favara B. Langerhans cell histiocytosis: lack of a viral etiology. Am J Hematol. 1994;47:16-20.

6. Jeziorski E, Senechal B, Molina TJ, Devez F, Leruez-Ville M, Morand P. Herpes-virus infection in patients with Langerhans cell histiocytosis: a case-controlled sero-epidemiological study, and in situ analysis. PLoS One. 2008;3:e3262.

7. Grois N, Pötschger U, Prosch $\mathrm{H}$, Minkov M, Arico M, Braier J, et al. DAL$\mathrm{HX}$ - and LCH I and II Study Committee risk factors for diabetes insipidus in Langerhans cell histiocytosis. Pediatr Blood Cancer. 2006;46:228-33.

8. Rojas R, García C, Parra D, Solar A, Oyanedel R, Díaz F, et al. Compromiso óseo en histiocitosis de células de Langerhans en el niño. Estudio radiológico simple. Presentación clínica y diagnóstico radiológico. Rev Chil Radiol. 2005;11:122-8.

9. Ibarra de la Torre A, Anaya Jara M, Rodríguez Jurado R. Histiocitosis de células de Langerhans vertebral con compresión medular en un infante. Arch Neurocien. 2010;15:194-8.

10. Aricò M, Girschikofsky M, Généreau T, Klersy C, McClain K, Grois N, et al. Langerhans cell histiocytosis in adults. Report from the International Registry of the Histiocyte Society. Eur J Cancer. 2003;39:2341-8.

11. Luong Tai C, Scrigni A, Paglia M, Garavaglia M, Aisenberg N, Rowensztein H, et al. Histiocitosis de células de Langerhans con compromiso vertebral y de partes blandas: caso clínico. Arch Argent Pediatr. 2016;114:256-9.

12. Garg S, Metha S, Dormans JP. Langerhans cell histiocytosis of the spine in children. Long-term follow-up. J Bone Joint Surg Am. 2004;86-A:1740-50.

13. Huang WD, Yang XH, Wu ZP, Huang Q, Xiao JR, Yang MS, et al. Langerhans cell histiocytosis of spine: a comparative study of clinical, imaging features, and diagnosis in children, adolescents, and adults. Spine J. 2013;13:1108-17.

14. Allen CE, Ladisch S, McClain KL. How I treat Langerhans cell histiocytosis. Blood. 2015;126:26-35.

15. Histiocyte Society. Langerhans cell histiocytosis: Histiocyte Society evaluation and treatment guidelines. 2009. Disponible en: https://histiocytesociety.org/document.doc?id=290

16. Vaiselbuh SR, Bryceson YT, Allen CE, Whitlock JA, Abla O. Updates on histiocytic disorders. Pediatr Blood Cancer. 2014;61:1329-35.

17. Minkov M, Steiner M, Pötschger U, Aricò M, Braier J, Donadieu J, et al. Reactivations in multisystem Langerhans cell histiocytosis: data of the international LCH registry. J Pediatr. 2008;153:700-5. 